The International Journal of

Interdisciplinary

Educational Studies

European Researchers' Night as a Learning Environment

JOSEPH ROCHE, NICOLA DAVIS, MARK CHAIKOVSKY, SHAUN O'BOYLE, AND CLIONA O'FARRELLY 
EDITOR

Gerassimos Kouzelis, University of Athens, Greece

HEAD OF JOURNAL PRODUCTION

McCall Macomber, Common Ground Research Networks, USA

EDITORIAL ASSISTANT

Hannah Werner, Common Ground Research Networks, USA

\section{ADVISORY BOARD}

The Interdisciplinary Social Sciences Research Network recognizes the contribution of many in the evolution of the Research Network. The principal role of the Advisory Board has been, and is, to drive the overall intellectual direction of the Research Network. A full list of members can be found at http://thesocialsciences.com/about/advisory-board.

\section{PEER REVIEW}

Articles published in The International Journal of Interdisciplinary Educational Studies are peer reviewed by scholars who are active participants of the Interdisciplinary Social Sciences Research Network or a thematically related Research Network. Reviewers are acknowledged in the corresponding volume of the journal. For a full list of past and current Reviewers, please visit http://thesocialsciences.com/journals/editors.

\section{ARTICLE SUBMISSION}

The International Journal of Interdisciplinary Educational Studies publishes quarterly (March, June, September, December). To find out more about the submission process, please visit http://thesocialsciences.com/journals/call-for-papers.

\section{THE INTERNATIONAL JOURNAL OF}

\section{INTERDISCIPLINARY EDUCATIONAL STUDIES}

http://thesocial sciences.com

ISSN: 2327-011X (Print)

ISSN: $2327-2570$ (Online)

http://doi.org/10.18848/2327-011X/CGP (Journal)

First published by Common Ground Research Networks in 2018 University of Illinois Research Park

2001 South First Street, Suite 202

Champaign, IL 61820 USA

$\mathrm{Ph}:+1-217-328-0405$

http://cgnetworks.org

The International Journal of Interdisciplinary

Educational Studies is a peer-reviewed, scholarly journal.

\section{COPYRIGHT}

(C) 2018 (individual papers), the author(s)

(C) 2018 (selection and editorial matter),

Common Ground Research Networks

All rights reserved. Apart from fair dealing for the purposes of study, research, criticism, or review, as permitted under the applicable copyright legislation, no part of this work may be reproduced by any process without written permission from the publisher. For permissions and other inquiries, please contact support@cgnetworks.org.

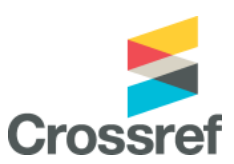

Common Ground Research Networks, a member of Crossref

\section{ABSTRACTING AND INDEXING}

For a full list of databases in which this journal is indexed, please visit http://thesocialsciences.com/journals/collection.

\section{RESEARCH NETWORK MEMBERSHIP}

Authors in The International Journal of Interdisciplinary Educational Studies are members of the Interdisciplinary Social Sciences Research Network or a thematically related Research Network. Members receive access to journal content. To find out more, visit http://thesocialsciences.com/about/become-a-member.

\section{SUBSCRIPTIONS}

The International Journal of Interdisciplinary Educational Studies is available in electronic and print formats. Subscribe to gain access to content from the current year and the entire backlist. Contact us at support@cgnetworks.org.

\section{ORDERING}

Single articles and issues are available from the journal bookstore at http://cgscholar.com/bookstore.

\section{HYBRID OPEN ACCESS}

The International Journal of Interdisciplinary Educational Studies is Hybrid Open Access, meaning authors can choose to make their articles open access. This allows their work to reach an even wider audience, broadening the dissemination of their research. To find out more, please visit http://thesocialsciences.com/journals/hybrid-open-access.

\section{DISCLAIMER}

The authors, editors, and publisher will not accept any legal responsibility for any errors or omissions that may have been made in this publication. The publisher makes no warranty, express or implied, with respect to the material contained herein. 


\title{
European Researchers' Night as a Learning Environment
}

\author{
Joseph Roche, ${ }^{1}$ Trinity College Dublin, Ireland \\ Nicola Davis, Trinity College Dublin, Ireland \\ Mark Chaikovsky, Trinity College Dublin, Ireland \\ Shaun O'Boyle, Trinity College Dublin, Ireland \\ Cliona O'Farrelly, Trinity College Dublin, Ireland
}

\begin{abstract}
European Researchers' Night is an annual pan-European initiative of the European Commission held on the last Friday in September. In 2015, 1.1 million European citizens and 18,000 researchers took part in events organised in more than 300 cities within Europe and neighbouring countries. The objective of European Researchers' Night is to encourage the wider public to visit research institutes, engage with researchers, and learn more about European research and potential career opportunities. In this paper, European Researchers' Night in Ireland is considered through the lens of informal education. The types of learning taking place at European Researchers' Night events are explored, and recommendations are made on how learning might be better assessed at future events.
\end{abstract}

Keywords: European Researchers' Night, Informal Education, Public Engagement

\section{Background to European Researchers' Night}

$\mathrm{E}$ uropean Researchers' Night takes place in at least 300 cities across more than thirty countries in Europe each year. It was first implemented as an initiative of the European Commission in 2005 and has been included in successive funding streams ever since (including the sixth Framework Programme, FP6, and its successors, FP7 and Horizon 2020). The cumulative funding made available for European Researchers' Night through these funding streams is approximately $€ 40$ million. The goals of the initiative are to bring researchers closer to the general public, increase awareness of European research, support the public recognition of researchers, create an understanding of the impact of researchers' work on citizens' daily life, and encourage young people to embark on scientific careers (EC 2014). Simultaneous events across Europe take place on the last Friday in September, and in 2015 the initiative engaged 1.1 million European citizens and 18,000 researchers (EC 2017). The events themselves can include tours, workshops, lectures, demonstrations, debates, and discussions.

In this paper, results are presented from an evaluation of European Researchers' Night in Ireland in 2015. The event was hosted by Trinity College Dublin in partnership with the Royal College of Surgeons in Ireland. Visitors to the event had the opportunity to see diverse research environments and participate in interactive installations, debates, tours, and presentations in four subject areas: human, technology, world, and society (RCSI 2015). In addition, visitors had the chance to engage directly with some of the country's leading researchers in such areas as robotics, neuroscience, and zoology. Although similar types of public engagement events take place in Ireland (see Roche, Cullen, and Ball 2016; Roche, Stanley, and Davis 2016), European Researchers' Night is the only event that makes labs and research centres publicly accessible for one night each year. While the primary focus of the evaluation was to better understand the attendees of the event, a secondary component involved exploring the informal learning that takes place at European Researchers' Night. Informal learning is "usually intentional but not highly structured" (Marsick and Watkins 2001, 25). Over the last two decades, informal science

${ }^{1}$ Corresponding Author: Joseph Roche, Room 3087, Arts Building, School of Education, Trinity College Dublin, Dublin 2, Ireland. email: Joseph.Roche@tcd.ie

The International Journal of Interdisciplinary Educational Studies

Volume 13, Issue 1, 2018, http://thesocialsciences.com

(C) Common Ground Research Networks, Joseph Roche, Nicola Davis, Mark Chaikovsky,

Shaun O'Boyle, Cliona O'Farrelly, All Rights Reserved.

Permissions: support@cgnetworks.org

ISSN: 2327-011X (Print), ISSN: 2327-2570 (Online)

http://doi.org/10.18848/2327-011X/CGP/v13i01/1-9 (Article) 
learning has become a growing field of research. Falk and Dierking (2000) provided a general framework for understanding informal or free-choice learning - a contextual model of learningwhich focuses on such aspects as agenda, personal motivation, and the sociocultural nature of learning. In 2009, the National Research Council pointed out some of the issues with the field of informal science learning: "There are a range of perspectives in research on learning science in informal environments which, despite clear similarities and areas of overlap, have not been well integrated into a common body of knowledge" (NRC 2009, 49). In 2016, the Center for Advancement of Informal Science Education documented how "growth in infrastructure for the [informal science education] field over the past 10 years has created new resources, capacity and expertise that can be leveraged to engage public audiences with the products and processes of research" (Bell et al. 2016, 4). European Researchers' Night represents an ideal event to explore informal science learning because it is an annual pan-European event that has been running for more than a decade and will likely be funded for the foreseeable future.

\section{Research Questions}

Considering the amount of funding being made available to invest in European Researchers' Night events, it is appropriate to consider the educational impact (if any) of the initiative. To help evaluate the impact of European Researchers' Night, two research questions were developed:

1. What do people learn about research at European Researchers' Night events?

2. What can be done to improve European Researchers' Night as a learning experience across Europe?

These research questions were developed by investigating European Researchers' Night as an educational endeavour that focuses on engaging European citizens with current research.

\section{Methods}

The methodology for this research stemmed from the evaluation of European Researchers' Night in Ireland. The full evaluation involved a mixed-methods approach consisting of surveys, observations, and focus groups. This paper focuses on a specific question in the survey: "At this event, did you find out something that you did not know before, and if so, what did you find out?" Additional results from the surveys, observations, and focus groups are described in Roche et al. (2017).

To address the research questions, it was necessary to understand if visitors to European Researchers' Night felt like they had learned anything new. A simple, open question in the survey was considered the best way to gather meaningful data. Although simple, open questions are more demanding for the respondent and the researcher analysing the answers, they are needed when the potential replies are too numerous to predict or are unknown (Kelley et al. 2003).

Data gathered from the open question were analysed using content analysis. Content analysis "is a research technique for making replicable and valid inferences from texts to the contents of their use" (Krippendorff 2004, 18). Although content analysis was first introduced in Scandinavia in the eighteenth century (Rosengren 1981), it has become a staple tool for evaluating public engagement events in recent decades. It transitioned to the field of public engagement after being first established as a research tool in health studies (Nandy and Sarvela 1997).

The rationale for carrying out a content analysis on the data gathered at European Researchers' Night was the strong inferential value of content analysis for analysing communications. It facilitates the study of social events without being obtrusive, and it can be used to analyse large amounts of information while remaining efficient and accessible (Babbie 2015). A drawback of using this method is its reliability-biases can affect researchers, 
respondents, and content, and this needs to be taken into account by ensuring intercoder reliability (Lincoln and Guba 1985). This was addressed by having three researchers independently code the data gathered at European Researchers' Night.

A conventional content analysis was undertaken, with the keywords and codes derived from the data itself (Hsieh and Shannon 2005). Other forms of content analysis such as directed or summative were considered unsuitable as there was not enough prior research published on informal learning at European Researchers' Night to appropriately define the codes in advance.

\section{Results}

On the night of European Researchers' Night in Ireland in 2015 (September 25), 242 people completed a visitor survey. One of the questions on the survey was an open-ended question that invited visitors to share details of anything new that they had learned: "At this event, did you find out something that you did not know before, and if so, what did you find out?" Figure 1 shows that 16.9 percent of participants chose to leave this question blank. Although 25.2 percent of participants answered in the negative, most of these respondents indicated that they had just arrived at the event.

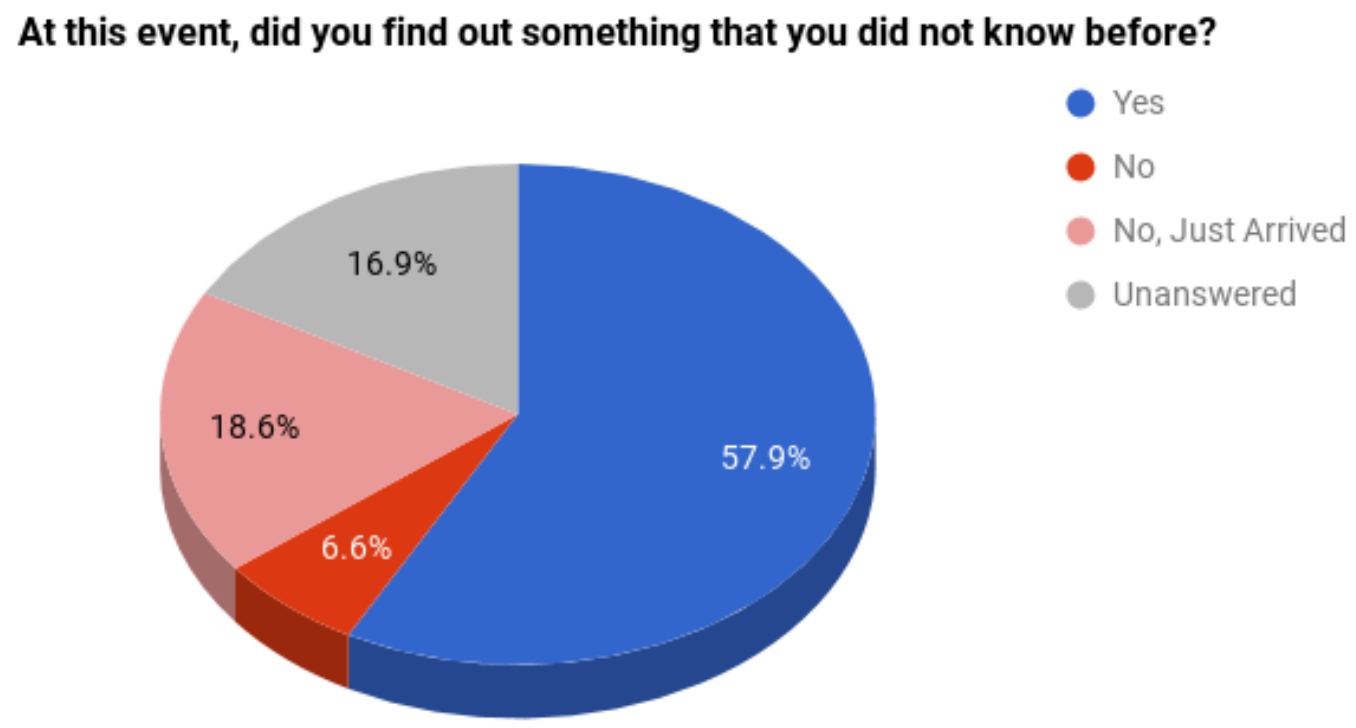

Figure 1: Self-Reported Informal Learning at European Researchers' Night. Data Compiled by the Authors

The activities that took place at the European Researchers' Night event were diverse and varied. The Appendix shows a list of events that were suggested to researchers to help them consider activities to run on European Researchers' Night. Figure 2 shows that the most common topics of informal learning indicated by the visitors at European Researchers' Night were in the areas of medicine and biomedical science. The next most common area of learning was research practice. 


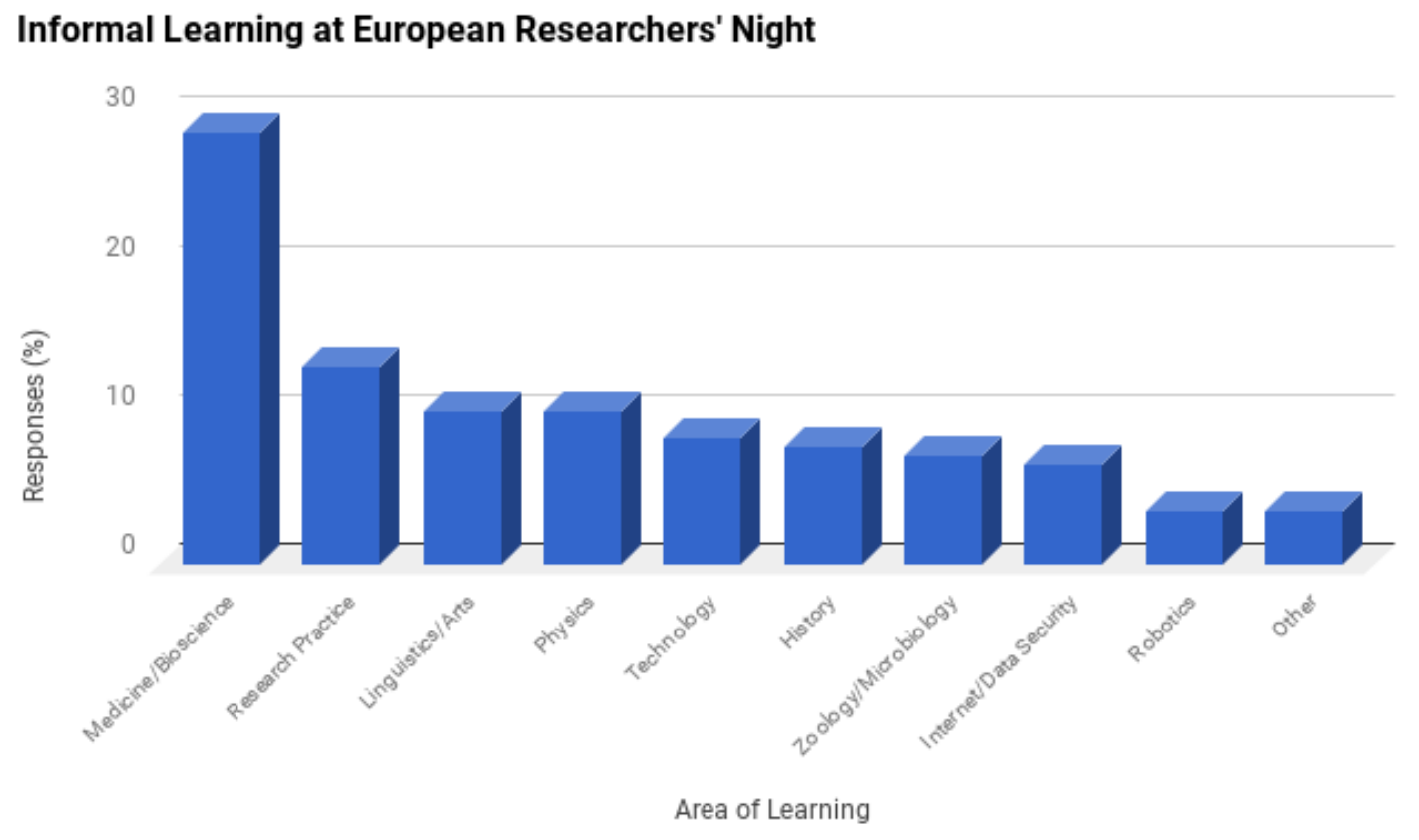

Figure 2: The Types of Informal Learning at European Researchers' Night. Participants' Open-Ended Answers Were Organized into the Ten Categories Shown. Data Compiled by the Authors

\section{Discussion and Conclusion}

Of the 242 surveyed visitors to European Researchers' Night, 57.9 percent indicated that they had found out something at the event that they did not know beforehand. This provides a crude approximation that European Researchers' Night itself is functioning as an informal learning event. It is likely that a larger number would have responded that they had learned something new if they had been approached later in the event, as most (73\%) of those who reported not learning something indicated that they had just arrived at the event (Figure 1).

The range of topics mentioned by the visitors helps to address the first of the research questions: "What do people learn about research at European Researchers' Night events?" The main areas of learning were medicine, health, and biomedical science, with at least twice as much self-reported learning in these areas compared to the other observed areas (Figure 2). Several factors might have influenced why this area was the most common area of learning. The expertise and research interests of the organisers, who were based in the Trinity Biomedical Sciences Institute, perhaps led to more researchers (and more motivated researchers) from the biomedical sciences and bioengineering participating in the event activities. This, coupled with the involvement of the Royal College of Surgeons in Ireland, could potentially have brought an intrinsic medicine, health, and biomedical science bias to the event. However, it is also plausible that the visitors to the event were naturally more interested in learning about topics involving health, as it is traditionally the area of research that receives the most support and interest from members of the public who are not involved in research themselves.

The second most common area of learning was "research practice." This included visitors who indicated that they had learned more about the process of research itself and how it is undertaken in an institution of higher education. This finding is in line with the European Commission's objectives for the event, which include "increased awareness among the general public of the importance of research and innovation" and a "better understanding of the key benefits that research brings to society" (EC 2017). Several constraints placed limitations on this research. The sample size of 242 visitors engaged on the night is a useful cross-section of the 
attendees, but given the overall attendance numbers of approximately 6,000 , it is likely that the sample size was below the targeted threshold of 10 percent of all visitors.

In relation to the second research question-"What can be done to improve European Researchers' Night as a learning experience across Europe?"- there are a number of obvious recommendations. European Researchers' Nights in Ireland will have to include locations other than Dublin in order to become a truly national event. A comprehensive study with students and young adults needs to be undertaken to assess whether all the objectives of European Researchers' Night are being met. It is likely that more attention will need to be given to connecting young people with researchers and providing them with a clear and honest illustration of career opportunities in Europe.

Although there were many different types of engagement activities at European Researchers' Night (see Appendix), the overall models of communication were still quite limited. Considering the engagement in terms of conventional frameworks of science communication models (Trench 2008), the communication that was taking place was often of the "deficit model" variety (in which visitors are considered "deficient" in knowledge on the topic in question) rather than the more democratic dialogue and participatory models of communication. This is not a new phenomenon and harks back to Arnstein's model of citizen participation, which imagined citizen participation as a ladder with its bottom rungs representing nonparticipation and the higher rungs affording increasing levels of control to citizens (Arnstein 1969). The need to strive towards more participatory models of communication is becoming a wider goal of public engagement events (Bultitude, McDonald, and Custead 2011). This is especially important in times of global political turmoil (Roche and Davis 2017).

Despite the fact that European Researchers' Night has been running for more than a decade, little has been published on what is working and what is not working. Only a few research groups have completed and shared in-depth evaluation reports regarding specific European Researchers' Night events - see Dimitrova (2010) and Sardo (2016) as rare examples. It is crucial that the wealth of learning taking place at the European Researchers' Night events across Europe are shared by the event organisers so that best practices can be followed and ineffective approaches be discontinued. Although European Researchers' Night coordinators in other countries are carrying out evaluations, there has not been a coordinated effort to share these evaluations and to publish the learnings and insights in peer-reviewed journals. Future work in this area will depend on the development of a network of European Researchers' Night evaluators. For European Researchers' Night to successfully achieve its goal of raising awareness of European research, it needs to have the same level of scrutiny and rigour applied to it as the research it promotes.

\section{Acknowledgement}

European Researchers' Night in Ireland was funded by the European Commission's Horizon 2020 research and innovation programme through the call: H2020-MSCA-NIGHT-2014 (Grant agreement no. 633292). The support of the Irish Research Council's New Foundations programme is acknowledged. The events themselves would not have happened without the support of the staff, students, and volunteers in Trinity College Dublin. 


\section{REFERENCES}

Arnstein, Sherry R. 1969. "A Ladder of Citizen Participation." Journal of the American Institute of Planners 35 (4): 216-24.

Babbie, Earl R. 2015. The Practice of Social Research. Boston: Cengage Learning.

Bell, Jamie, John Falk, Roxanne Hughes, Geoff Hunt, Julia Parrish, Monya Ruffin, Kalie Sacco, and Grace Troxel. 2016. "Informal STEM Education: Resources for Outreach, Engagement and Broader Impacts." Center for Advancement of Informal Science Education (CAISE). Accessed July 31, 2017. http://www.informalscience.org/sites /default/files/CAISE_Broader_Impacts_Report_2016_0.pdf.

Bultitude, Karen, Dominic McDonald, and Savita Custead. 2011. "The Rise and Rise of Science Festivals: An International Review of Organised Events to Celebrate Science." International Journal of Science Education, Part B 1 (2): 165-88.

Dimitrova, Krasimira. 2010. Impact Assessment of Researcher's Night 2010. Sofia: ATA48. Accessed July 31, 2017. http://www.ata48.com/wp-content/uploads/2013/10/Impact Analyses_RN_2010.pdf.

European Commission (EC). 2014. "Marie Skłodowska-Curie Actions." Horizon 2020 Work Programme 2014-2015. Accessed July 31, 2017. http://ec.europa.eu/programmes /horizon2020/en/h2020-section/marie-sklodowska-curie-actions.

2017. "European Researchers' Night 2017." European Commission: Research and Innovation. Accessed July 31, 2017. https://www.interregeurope.eu/ecoris3/news/news -article/2292/european-researchers-night/.

Falk, John H., and Lynn D. Dierking. 2000. Learning from Museums: Visitor Experiences and the Making of Meaning. Lanham, MD: Altamira Press.

Hsieh, Hsiu-Fang, and Sarah E. Shannon. 2005. "Three Approaches to Qualitative Content Analysis." Qualitative Health Research 15 (9): 1277-88.

Kelley, Kate, Belinda Clark, Vivienne Brown, and John Sitzia. 2003. "Good Practice in the Conduct and Reporting of Survey Research." International Journal for Quality in Health Care 15 (3): 261-66.

Krippendorff, Klaus. 2004. Content Analysis: An Introduction to its Methodology. Thousand Oaks, CA: SAGE Publications.

Lincoln, Yvonna S., and Egon G. Guba. 1985. Naturalistic Inquiry. Newbury Park, CA: SAGE Publications.

Marsick, Victoria J., and Karen E. Watkins. 2001. "Informal and Incidental Learning." New Directions for Adult and Continuing Education 89: 25-34.

Nandy, Bikash R., and P. D. Sarvela. 1997. "Content Analysis Reexamined: A Relevant Research Method for Health Education." American Journal of Health Behavior 21 (3): 222-34.

National Research Council (NRC). 2009. Learning Science in Informal Environments: People, Places, and Pursuits. Washington, DC: National Academies Press.

RCSI: Royal College of Surgeons in Ireland. 2015. "Discover Research Dublin 2015 to Open Eyes and Minds to the Amazing World of Irish Research." RCSI. Accessed July 31, 2017. http://www.rcsi.ie/index.jsp? $\mathrm{a}=6341 \& \mathrm{n}=2342 \& \mathrm{p}=164$.

Roche, Joseph, Ronan J. Cullen, and Sarah-Louise Ball. 2016. "The Educational Opportunity of a Modern Science Show.” International Journal of Science in Society 8 (3): 21-30.

Roche, Joseph, Jessica Stanley, and Nicola Davis. 2016. "Engagement with Physics across Diverse Festival Audiences." Physics Education 51 (4): 1-6. http://dx.doi.org/10.1088/0031-9120/51/4/045007.

Roche, Joseph, and Nicola Davis. 2017. "Should the Science Communication Community Play a Role in Political Activism?” Journal of Science Communication 16 (1): 1-4. 
Roche, Joseph, Nicola Davis, Shaun O'Boyle, Conor Courtney, and Cliona O'Farrelly. 2017. "Public Perceptions of European Research: An Evaluation of European Researchers' Night in Ireland." International Journal of Science Education Part B 7 (4): 374-91. https://doi.org/10.1080/21548455.2017.1371354.

Rosengren, Karl Erik. 1981. "Advances in Scandinavia Content Analysis: An Introduction.” In Advances in Content Analysis, edited by K. E. Rosengren, 9-19. Beverly Hills, CA: SAGE Publications.

Sardo, Margarida. 2016. "Evaluation of the Bristol Bright Night 2015 (BBN15)." University of the West of England. Accessed July 31, 2017. http://eprints.uwe.ac.uk/28806/.

Trench, Brian. 2008. "Towards an Analytical Framework of Science Communication Models." In Communicating Science in Social Contexts, edited by D. Cheng, M. Claessens, T. Gascoigne, J. Metcalfe, B. Schiele, and S. Shi, 119-35. Brussels, Belgium: New Models New Practice.

\section{APPENDIX}

Table 1.1: Event Formats

\begin{tabular}{|l|l|l|l|}
\hline Event & Description & $\begin{array}{l}\text { Audience } \\
\text { (Min-Max) }\end{array}$ & $\begin{array}{l}\text { Production } \\
\text { Level }\end{array}$ \\
\hline Auction & $\begin{array}{l}\text { Audience "bids" on ideas or projects that are pitched } \\
\text { to them }\end{array}$ & $5+$ & LOW \\
\hline Cabaret & $\begin{array}{l}\text { Mixes music, song, dance and drama with an } \\
\text { overarching theme }\end{array}$ & $20-100$ & HIGH \\
\hline Debate & $\begin{array}{l}\text { Facilitate healthy and real debate within a research } \\
\text { topic }\end{array}$ & $20-50$ & LOW \\
\hline $\begin{array}{l}\text { Pop-Up } \\
\text { Exhibition }\end{array}$ & $\begin{array}{l}\text { Small exhibition of research equipment, images, or } \\
\text { outputs }\end{array}$ & $30+$ & HIGH \\
\hline Street Feast & Everyone brings and shares food for social gathering & $10-30$ & HIGH \\
\hline Forum & Airing of differing opinions along a specific theme & $20-50$ & LOW \\
\hline Gig & Stage performance by band or comedian & $40-80$ & HIGH \\
\hline Hackathon & $\begin{array}{l}\text { Collaborate to build a prototype within a set period } \\
\text { of time }\end{array}$ & $7-15$ & MEDIUM \\
\hline Improv & $\begin{array}{l}\text { Unscripted comedy performance with audience } \\
\text { contribution }\end{array}$ & $30-60$ & MEDIUM \\
\hline Interview & $\begin{array}{l}\text { One-on-one discussion with researcher on chosen } \\
\text { topic }\end{array}$ & $40-200$ & MEDIUM \\
\hline Open Mic & Sign up for talk or performance just before it starts & $20-50$ & MEDIUM \\
\hline $\begin{array}{l}\text { Panel } \\
\text { Discussion }\end{array}$ & Classic side-by-side cross-disciplinary discussion & $40-200$ & MEDIUM \\
\hline Performance & Theatre, dance or music performances & $20-200$ & HIGH \\
\hline
\end{tabular}


THE INTERNATIONAL JOURNAL OF INTERDISCIPLINARY EDUCATIONAL STUDIES

Table 1.2: Event Formats Continued

\begin{tabular}{|c|c|c|c|}
\hline Event & Description & $\begin{array}{l}\text { Audience } \\
\text { (Min-Max) }\end{array}$ & $\begin{array}{l}\text { Production } \\
\text { Level }\end{array}$ \\
\hline Screening & Screening of a film or documentary in a theatre & $10-200$ & LOW \\
\hline Listening Event & $\begin{array}{l}\text { Curated, hosted event during which the audience } \\
\text { listens to radio pieces }\end{array}$ & $15-50$ & MEDIUM \\
\hline Quiz & Challenge style event-host, teams, and tournament & $30-100$ & HIGH \\
\hline Talk & Classic, straight-up talk on a specific theme & $50-200$ & MEDIUM \\
\hline Situation Room & $\begin{array}{l}\text { Gather to discuss important issue, with solid plan as } \\
\text { an outcome }\end{array}$ & $50-200$ & HIGH \\
\hline Silent Disco & $\begin{array}{l}\text { Everyone listening to the same set / performance on } \\
\text { headphones }\end{array}$ & $5-20$ & MEDIUM \\
\hline Unconference & $\begin{array}{l}\text { Agenda decided at beginning of conference by } \\
\text { participants }\end{array}$ & $20-60$ & HIGH \\
\hline Walking Tour & $\begin{array}{l}\text { Guided tour around specific research-related } \\
\text { buildings / sites }\end{array}$ & $5-15$ & LOW \\
\hline Workshop & $\begin{array}{l}\text { Hands-on session where visitors learn a skill and } \\
\text { make something }\end{array}$ & $1-15$ & MEDIUM \\
\hline Lightning Talks & $\begin{array}{l}\text { A fast succession of "elevator pitch" talks lasting } \\
\text { between one and ten minutes; no multimedia }\end{array}$ & $20-60$ & HIGH \\
\hline $\begin{array}{l}\text { Ignite / } \\
\text { Pecha Kucha }\end{array}$ & $\begin{array}{l}\text { A talk lasting about five minutes, with slides every } \\
\text { fifteen or twenty seconds }\end{array}$ & $20-60$ & HIGH \\
\hline Speed Geeking & $\begin{array}{l}\text { Like speed networking, but pitching a big idea to a } \\
\text { small group }\end{array}$ & $5-25$ & MEDIUM \\
\hline Demonstration & $\begin{array}{l}\text { Short "shows" during which researchers } \\
\text { demonstrate equipment or method }\end{array}$ & $1-15$ & MEDIUM \\
\hline Soundclash & $\begin{array}{l}\text { Two groups "battle" with different approaches to the } \\
\text { same thing }\end{array}$ & $20-200$ & HIGH \\
\hline Crowdsource & Installation of ideas or suggestions from audience & $20+$ & MEDIUM \\
\hline Lost Lectures & $\begin{array}{l}\text { Talk in secret, unusual location announced just } \\
\text { before it happens }\end{array}$ & $5-15$ & MEDIUM \\
\hline Cinema Royal & Film screening in unoccupied or unusual location & $5-15$ & MEDIUM \\
\hline $\begin{array}{l}\text { Silent } \\
\text { Conference }\end{array}$ & Like silent disco, but with talks and discussions & $5-20$ & HIGH \\
\hline $\begin{array}{l}\text { Live } \\
\text { Documentary }\end{array}$ & $\begin{array}{l}\text { Mix live, Skype, and pre-recorded interviews that } \\
\text { explore a theme }\end{array}$ & $60-200$ & HIGH \\
\hline Group Build & $\begin{array}{l}\text { Visitors participate in the building of a giant } \\
\text { structure or performance }\end{array}$ & $20+$ & HIGH \\
\hline Fishbowl & $\begin{array}{l}\text { Chairs in concentric circles around one volunteer } \\
\text { and three panellists }\end{array}$ & $20-60$ & HIGH \\
\hline World Café & $\begin{array}{l}\text { Cumulative brainstorms at tables for four or five } \\
\text { people for twenty minutes }\end{array}$ & $20-40$ & HIGH \\
\hline
\end{tabular}


ROCHE ET AL.: EUROPEAN RESEARCHERS' NIGHT AS A LEARNING ENVIRONMENT

Table 1.3: Event Formats Continued

\begin{tabular}{|l|l|l|l|}
\hline Event & Description & $\begin{array}{l}\text { Audience } \\
\text { (Min-Max) }\end{array}$ & $\begin{array}{l}\text { Production } \\
\text { Level }\end{array}$ \\
\hline $\begin{array}{l}\text { Start-Up } \\
\text { Evening }\end{array}$ & $\begin{array}{l}\text { An intense session where people collaborate on a } \\
\text { new start-up }\end{array}$ & $5-20$ & HIGH \\
\hline Editathon & Group editing session on specific Wikipedia entries & $5-20$ & LOW \\
\hline Visualisation & $\begin{array}{l}\text { A wall of illustrations and flowcharts describing } \\
\text { event content and ideas }\end{array}$ & $20+$ & MEDIUM \\
\hline Curated Dinner & $\begin{array}{l}\text { Chef and researcher collaborate to create a themed } \\
\text { dinner }\end{array}$ & $15-20$ & HIGH \\
\hline Party & $\begin{array}{l}\text { Blend of exhibits, demos, music, talks, and } \\
\text { performances-all after hours }\end{array}$ & $100-300$ & HIGH \\
\hline Live Recording & $\begin{array}{l}\text { Recording of a podcast or radio show in front of a } \\
\text { live audience }\end{array}$ & $20-100$ & HIGH \\
\hline Home-School & Learn from an expert how to do something at home & $5-20$ & MEDIUM \\
\hline Career Talks & Interviews or talks on different career progressions & $20-60$ & MEDIUM \\
\hline Meet-Up & Facilitate a social meet-up of like-minded people & $20-40$ & LOW \\
\hline $\begin{array}{l}\text { TED-Style } \\
\text { Talks }\end{array}$ & $\begin{array}{l}\text { Fifteen-minute, rehearsed, and highly prepared talks } \\
\text { on ideas }\end{array}$ & $100-200$ & HIGH \\
\hline Taxi & Simulate a conversation in the front of a taxi & $2-4$ & LOW \\
\hline $\begin{array}{l}\text { Moth-Style } \\
\text { Talks }\end{array}$ & $\begin{array}{l}\text { Storytelling to celebrate diversity and commonality } \\
\text { of human experience }\end{array}$ & $20-100$ & HIGH \\
\hline
\end{tabular}

Science Gallery Dublin, Trinity College Dublin 2015

\section{ABOUT THE AUTHORS}

Joseph Roche: Assistant Professor, School of Education, Trinity College Dublin, Dublin, Ireland

Nicola Davis: Research Assistant, School of Education, Trinity College Dublin, Dublin, Ireland

Mark Chaikovsky: Research Assistant, School of Education, Trinity College Dublin, Dublin, Ireland

Shaun O'Boyle: Research Coordinator, Science Gallery Dublin, Trinity College Dublin, Dublin, Ireland

Cliona O'Farrelly: Professor, School of Biochemistry and Immunology and School of Medicine, Trinity College Dublin, Dublin, Ireland 


\section{The International Journal of Interdisciplinary}

Educational Studies is one of seven thematically focused journals that support the Interdisciplinary Social Sciences Research Network. The Research Network is comprised of a journal collection, book imprint, conference, and online community.

The journal presents studies that exemplify the disciplinary and interdisciplinary practices of the social sciences. As well as articles of a traditional scholarly type, this journal invites case studies that take the form of presentations of practice-including documentation of socially engaged practices and exegeses analyzing the effects of those practices.

The International Journal of Interdisciplinary

Educational Studies is a peer-reviewed, scholarly journal. 